\title{
EXPLORING THE IMPACT OF SAP VERSION 10 ON THE UK CONSTRUCTION INDUSTRY
}

\author{
E Skoufoglou *1 BEng MSc MBA CEng MIET AMILP, F Hagan ${ }^{2}$ BEng MEng \\ ${ }^{1}$ ithaca 7 engineers \& designers ltd, London, UK \\ ${ }^{2}$ boom collective ltd, London, UK \\ * Corresponding Author
}

\begin{abstract}
On 27th of July 2018 the BEIS (Business Energy And Industrial Strategy) and BRE (Building Research Establishment) published SAP version 10; the eagerly awaited update to the current SAP2012, the Standard Assessment Procedure, otherwise known as SAP, is the industry standard calculation methodology used to demonstrate the energy performance of dwellings in the UK and is a key part of building regulations compliance.

The limitations of the current calculation methodology have been a talking point in recent years, resulting in much anticipation for a more comprehensive building regulations compliance methodology for dwellings. One of the most significant changes between SAP10 and SAP2012 is the alignment of carbon factors with reality. Current SAP assumes that the electricity used, produces 2.4 times the carbon emissions of mains gas. SAP10 introduces a 55\% reduction in the $\mathrm{CO}_{2}$ emissions factor for electricity, meaning dwellings heated by direct electric systems will essentially produce the same $\mathrm{CO}_{2}$ emissions as gas.

The acknowledgement of 'greener electricity' is just one of the key changes with the proposed new SAP10. There is no doubt that this updated calculation methodology will challenge the current preferred environmental strategies for compliance for new dwellings in the UK. This paper explores the impact of SAP version 10 on the UK construction industry and intends to highlight the key differences between SAP10 and SAP2012, focusing on the major changes that will potentially affect the way that we design our dwellings going forward.
\end{abstract}

\section{Notation}

SAP: the Standard Assessment Procedure

BEIS: Business Energy And Industrial Strategy

BRE: Building Research Establishment)

PEA: Predicted Energy Assessment

EPC: Energy Performance Certificate

FITs: Feed In Tariffs

BACS: Building Automation \& Controls Systems

TBM: Technical Building Management

\section{Introduction}

The Standard Assessment Procedure (SAP) is the methodology used by the Government to assess and compare the energy and environmental performance of dwellings.

On 24th of July 2018 the BEIS (Business Energy and Industrial Strategy) and BRE (Building Research Establishment) published SAP Version 10; the eagerly awaited update to the current SAP2012.

The limitations of the current calculation methodology have been a talking point in recent years, resulting in much anticipation for a more comprehensive building regulations compliance methodology for dwellings.

There are a number of changes that will affect energy assessments in the future; however it is difficult to estimate their full impact on building regulations compliance, as SAP10 will not be introduced until there is a change in building regulations.

Whilst SAP10 has now been published, it will only supersede the current SAP2012 when the building regulation Part L, is next updated, likely to be this year or next.

Notably the Greater London Authority has already adopted the change in carbon factors for calculating carbon compliance for the energy statement of the planning process of major projects.

This paper highlights the major changes between SAP10 and SAP2012, exploring the impact on the UK construction industry and how it will potentially affect the way that we design our dwellings going forward.

Will the key changes of SAP10 influence the appraisal of low zero carbon technology options for new homes? How significant will adopting mature building technologies, such as intelligent building systems, become in meeting compliance?

Could SAP10 trigger further innovation in construction, and what would be its impact on construction methods, offsite manufacturing and asset management? 


\section{Standard Assessment Procedure (SAP)}

\subsection{History}

SAP was developed by the Building Research Establishment (BRE) for the former Department of the Environment in 1992, as a tool to help deliver its energy efficiency policies. In 1994 SAP was cited in Part L of the Building regulations as a means of assessing dwelling performance. Reduced Data SAP was introduced in 2005 as a lower cost method of assessing the energy performance of existing dwellings.

SAP2012 is the current revision of the SAP document.

In November 2016, the Government consulted on changes to how SAP (including Reduced Data SAP) assesses the energy performance of homes, to keep pace with research, innovation and technology developments. The SAP consultation included technical documents that gave reasoning behind the main changes, as well as some discussion of likely impact. This revision was to be referred to as SAP10.

On 24th of July 2018 BEIS and BRE published SAP Version 10; the eagerly awaited update to the current SAP2012.

\subsection{How it works}

SAP works by assessing how much energy a dwelling will consume, when delivering a defined level of comfort and service provision. The assessment is based on standardised assumptions for occupancy and behaviour. This enables a like-for-like comparison of dwelling performance. Related factors, such as fuel costs and emissions of carbon dioxide (CO2), can be determined from the assessment.

SAP quantifies a dwelling's performance in terms of: energy use per unit floor area, a fuel-cost-based energy efficiency rating (the SAP Rating) and emissions of $\mathrm{CO} 2$ (the Environmental Impact Rating). These indicators of performance are based on estimates of annual energy consumption for the provision of space heating, domestic hot water, lighting and ventilation.

A SAP rating is the calculation that is required in order to produce a Predicted Energy Assessment (PEA) and an on construction Energy Performance Certificate (EPC). Building Regulations require that a SAP calculation and a PEA is submitted for new dwellings prior to the commencement of work.

A SAP calculation indicates a score from 1 to $100+$ for the annual energy cost based on:

- The elements of structure;

- The heating and hot water system;

- The internal lighting;

- The renewable technologies used in the home.
The higher the score the lower the running costs, with 100 representing zero energy cost. Dwellings with a rating in excess of 100 are net exporters of energy. SAP calculations allow comparison to be made of the energy running costs of dwellings anywhere in the UK and are based upon a notional standard occupancy that overcomes variations associated with physical location and the differing ways in which people utilise their homes.

\section{SAP10 vs SAP2012 Key Changes}

Many of the SAP changes were originally outlined in BEIS' Proposed Changes to Government's SAP (November 2016). This was known as the DRAFT SAP2016 but was never implemented.

Technical Note 05 , produced by the BRE lists 18 changes between SAP2012 and the proposed new SAP10. Whilst these are all considered improvement to the industry standard calculation methodology, the following section focus' on the key changes only.

\subsection{Carbon Factors and Fuel Prices}

The changes to the electricity related carbon emissions may be the most significant factor - reducing from 0.519 $\mathrm{kgCO}_{2} / \mathrm{kWh}$ to $0.233 \mathrm{kgCO}_{2} / \mathrm{kWh}$, now only slightly higher than mains gas $(0.210)$. Currently SAP assumes that any electricity used produces 2.4 times the carbon emissions of mains gas -The 'greening of the grid' means there is now much more renewable and clean energy available, and much less coal being burned.

It is worth noting that these figures for $\mathrm{CO}_{2}$ emissions factors in SAP10 are far lower for electricity than in 2016.

Table 1 Change in $\mathrm{CO} 2$ emissions factors

\begin{tabular}{llcc}
\hline & \multicolumn{3}{c}{ Emissions $\mathrm{kgCO}_{2}$ per $\mathrm{kWh}$} \\
& SAP & Draft SAP & SAP \\
& 2012 & 2016 & 10 \\
\hline Mains Gas & 0.216 & 0.2077 & 0.210 \\
\hline Electricity & 0.519 & 0.3980 & 0.233 \\
\hline
\end{tabular}

The value of exported electricity in SAP10 is $3.8 \mathrm{p} / \mathrm{kWh}$, whereas the cost of grid electricity is $16.6 \mathrm{p} / \mathrm{kWh}$ on standard tariff. In SAP2012, exported solar electricity is assumed to be of the same value as electricity bought by the householder.

\subsection{Configuration of PV Panels}

SAP2012 used a fixed assumption for the proportion of electrical energy generated by Photovoltaic (PV) systems and consumed within the dwelling. This was attributed regardless of whether there was a direct connection to a dwelling, or whether, as is often the case on blocks of flats, only one exists to a landlords supply.

The Beta factor is the percentage of electricity generated by the PVs, that is used in the house. SAP2012 assumed a beta 
factor of $50 \%$ - meaning that $50 \%$ of generated electricity was used in the house and $50 \%$ exported.

As solar systems started to get larger, it became more apparent that this assumption was not a true reflection of real life. However, it wasn't significant because the value of exported electricity was the same as the saving made for energy not purchased from the grid.

For SAP10, the proportion of energy used in the house is now a function of the size of the solar system's energy output as a proportion of the energy demand. Larger solar systems attached to small energy demands will have a smaller beta factor and smaller solar systems attached to a large energy demand will have a higher beta factor. Adding a battery into the property will increase the beta factor.

\subsection{Hot Water Demand}

The calculation of hot water demand will now take into account the number of showers and baths which are present in a dwelling. It will also consider flow rates and whether showers are mains or electric fed. This will result in a more accurate assessment of hot water demand than currently in SAP2012, as well as resulting in higher energy use in dwellings with electric showers.

\subsection{Default distribution loss factors associated with heat networks have been increased}

SAP10 assumes higher heat losses from heat networks than SAP2012, unless the performance data has been entered into a Product Characteristics Database (PCDB).

If heat networks are not in the PCDB, the calculation methodology assumes a Distribution Loss Factors (DLF) of 1.5 , on the basis that the system is designed to the CIBSE Heat Networks: Code of Practice for the UK (CP1). If the code is not followed, a DLF of two must be used.

In summary, SAP10 assumes that half of the heat generated by the system is lost in the network.

Modern requirements have led to an increase in the demand of community heating networks. Traditional community heating technologies will not favour as well under the new SAP10 methodology, due to changes in the assessment.

\subsection{Heating Profile}

Currently SAP attributes a standard heating pattern which assumes that homes are heated differently on weekdays and weekends. Studies have shown that this is not necessarily the case in everyday life. SAP10 has been changed to apply a consistent daily pattern for all days of the week including weekends (see graphs $1 \& 2$ ).
SAP10 \& SAP2012: Daily Heating Pattern (weekday)

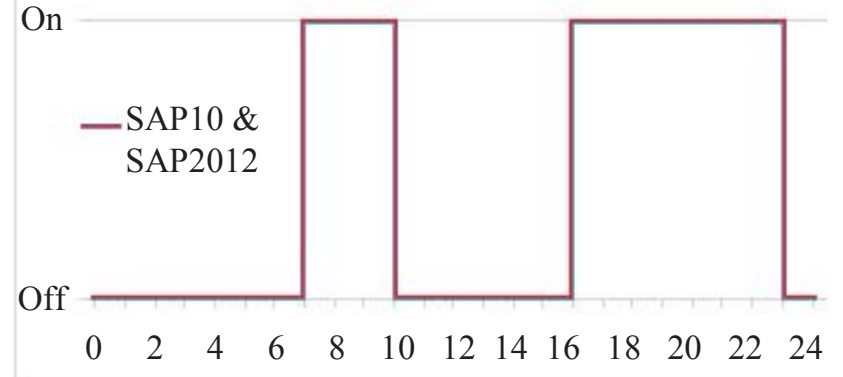

SAP10 \& SAP2012: Daily Heating Pattern (weekend)

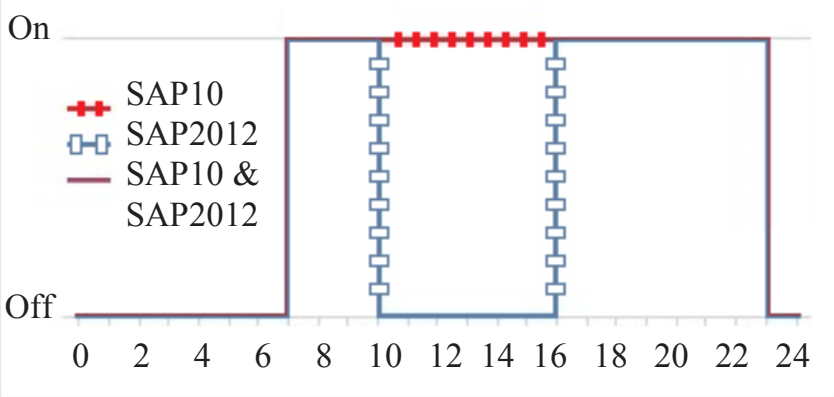

Graphs $1 \& 2$. Heating profiles showing differences between SAP2012 and SAP10

\subsection{Lighting}

The lighting simulation within the current SAP2012 is over simplified, considering only the number of low energy fittings being installed. The proposed new SAP10 calculation methodology has been updated in line with the Simplified Building Energy Model (SBEM) methodology and will allow recognition of new lighting types with higher efficacy.

\subsection{Overheating}

Appendix P of the SAP guidance details the assessment of internal temperatures in summer and overheating. The current assessment method is very basic and is primarily dependant on the energy assessor selecting an extent to which the windows can be open; Fully open results in no risk of overheating, while anything less results in potentially low, medium, high risk of overheating. SAP10 attempts to assess the risk of overheating slightly more accurately; reducing glazing and consequently heat gains, will become as significant as providing ventilation gains. On top of this, dwellings which are naturally ventilated, will now have to give consideration to noise and security as well.

Whilst these improvements are likely to flag up concerns for highly glazed penthouse apartments, it is strongly recommended that a more comprehensive overheating study is undertaken where high internal temperatures are anticipated. Thermal dynamic modelling using CIBSE environmental design parameters, and a consideration to 
future climate change and increased weather profiles would be the preferred industry standard.

\section{Impacts of the new SAP10}

The new SAP10 methodology for calculating energy use in new residential developments is set to have a significant impact on the way consultants design heating systems for the purpose of Building Regulations compliance.

A $55 \%$ reduction in the $\mathrm{CO}_{2}$ emissions factor for electricity, means dwellings heated by direct electric systems will essentially produce the same $\mathrm{CO}_{2}$ emissions as gas. Heat pumps will have even less carbon emissions. However, electricity is almost four times as expensive as gas and therefore this new carbon factor could unintendedly result in higher energy bills.

It is likely that developers will turn to either heat pumps, electric panel heaters and/or electric underfloor heating to provide heating, in place of the standard gas boiler. Combined Heat and Power (CHP) and district heating will also become less attractive to developers.

As well as this, the impact for solar photovoltaics is that solar systems will need to be more than double the size of current systems to produce the same carbon benefit in the calculation, which could reduce the competitiveness of solar PV as a means of meeting building regulations.

PV diverters can also be used in SAP10, to contribute towards energy for hot water, so long as a battery is not present and the hot water cylinder has a sufficient volume (more than daily demand).

In relation to [3.1 \& 3.2], the change in fuel prices does not affect the Dwelling Emissions Rate used for current building regulations. The presence of Solar PV panels will save carbon whether the electricity is used in the house or not.

These changes do, however, impact the SAP score and EPC band, as they impact on the calculation of the energy bills associated with the house.

As detailed in [3.5], the new heating pattern will likely mean better ratings for homes, as the heating will now be defaulted to being on less at the weekends.

Since the decarbonisation of our energy supply favours electric heating in dwellings, there is potential for modern construction methods to be pushed even further. Residential blocks continue to go up rapidly in many inner city areas, therefore lending itself to modular, prefabrication construction off-site. The ease with which electric underfloor heating could be added to such off-site construction, might become more appealing to developers.

\section{A critical review of SAP10}

\subsection{Carbon Factors}

The current UK energy infrastructure strategy has been based on nuclear and renewable energy sources for recent years, resulting in the decarbonisation of our energy supplies.

Whilst this has at last been recognised and subsequently updated in the proposed new SAP10 calculation methodology, we must remember that SAP10 is not likely to be fully implemented until approximately 2020 .

On top of this, with the recent changes in Feed In Tariffs (FITs) combined with the withdrawal of some of the key engineering companies from the UK's nuclear program (Toshiba in Cumbria and Hitachi in Wales), one might ask how realistic these carbon factor figures will actually be once they are fully implemented.

With a more short term view, these carbon intensity changes do not reflect the seasonality of such renewables with which are energy is supplied from. The solar farms in the UK will inevitably be generating electricity at a peak rate in the summer and then at a minimum rate in the winter. This is in contrast to the typical heating demand profile of a dwelling. Whilst the housing developers who are building large blocks of flats in inner city areas are likely to opt for electric heating - be it electric panel radiators and/or electric underfloor heating, combined with immersion heaters for hot water, the home owner is likely to find themselves paying larger utility bills.

\subsection{Heating}

The new heating profile has been adapted to reflect what is considered to be more indicative of how our homes are actually used on a weekly basis. That is, we are in our homes with the heating on (likely via timer switch) equally as much over the weekends as during the week.

It has been acknowledged that the new heating profile will likely mean better EPC ratings for dwellings. However, if electric underfloor heating is now to become favourable for developers as discussed in section 4 , this new heating profile is no longer a true reflection of how an underfloor heating system works. The benefits and advantages of underfloor heating come from the fact that it is on 24/7. Therefore a dwelling with electric underfloor heating, that is being assessed under SAP10 calculation methodology, will have an energy performance rating which is not reflective or comparable to its real life operation.

\subsection{Lighting}

As discussed in [3.6], the proposed changes in SAP10 will result in the use of a much more accurate lighting design and consequently a more accurate calculation of the carbon contribution relative to the lighting system.

Whilst this is towards to the correct direction at the new SAP's Appendix L, which describes the calculation of the 
energy for lighting and electrical appliances, the usage of the lighting system is not taken under consideration. The use of a profile usage similar to the one in the heating profile would align the SAP results closer to reality.

\subsection{Metering}

Metering allows owners, occupiers and operators to measure energy, water or heat consumption in their buildings on an hourly basis.

The government requires that all energy suppliers offer smart meters to homes \& businesses. However unlike Building Regulations PartL2 (for non-domestic commercial buildings over $500 \mathrm{~m}^{2}$ and every building over $1000 \mathrm{~m}^{2}$ ), it is not a legal requirement of Building Regulations Part L1. (domestic buildings)

As discussed in [5.1] the proposed changes in carbon factors with SAP10 are expected to affect the heating strategy and domestic hot water in many of the new developments.

For dwellings without a metering system, it will be more difficult to; identify energy and cost saving opportunities, provide accurate energy or water usage data or bills to tenants, assist with energy and emissions reporting requirements and to help the management of environmental and sustainability services and impacts.

CIBSE Technical Memorandum 39 (TM39): Building Energy Metering provides guidance on measurement of the 'consumption' of energy and heat for Non-domestic buildings only.

SAP10 could adopt a similar approach, to optimise the metering strategy against cost, practicality, the value of the information gained and future energy savings.

High electricity consumers such as electric panel radiators and/or electric underfloor heating should be metered in a zone by zone base to provide an in depth understanding of their usage and consumption.

\subsection{Protecting the green belt}

According to London Plan, London's land designated as Green Belt makes $22 \%$ of the total area. In attempt to protect it the mayor highlights in the London Plan how its dedesignation will not be supported in any circumstance.

The green belt extends in rural and off grid areas, which often served only from the electricity network. These sites under SAP2012 would strangle to meet the planning permission requirements of Zero Carbon due to the high associated carbon factors of electricity. With the decarbonisation of electricity new proposals would be more feasible and as result the protection of the green belts could be argued that it has been compromised.

\subsection{Post evaluation}

As it described in [2.2] SAP calculation is required in order to produce an EPC. Each EPC certificate is valid for 10years and following that period a renewal is required in the event that the owner would like to sell or rent the property. The new EPC will then be calculated from the current industry standard SAP methodology. This means that the value of the properties could be affected if the new SAP score is lower than that during the original EPC.

The Predictive EPC is based on design information only; therefore, is considered a targeted energy performance. Post construction, the calculation is run again based on exactly what has been installed and commissioned in the dwelling.

It might be proposed that renewing an EPC after the 10year period, is done based on actual metered performance rather than theorical performance data. This would take into account the unregulated energy use of a dwelling, which might typically result in approximately $25 \%$ increase in running costs of a dwelling.

\subsection{Smart Buildings in SAP10}

A Smart Building consists of Building Automation \& Controls Systems (BACS) and Technical Building Management (TBM). Apart from a fairly basic acknowledgement of heating controls, there is minimal reference to controls within the proposed new SAP10.

According to BS EN 15232 a Class A rated BACS and TBM solution in comparison to a standard Class $\mathrm{C}$ rated solution provides energy reduction of $18 \%$ overall in dwellings or $8 \%$ in electricity, $19 \%$ in thermal energy and $20 \%$ in domestic hot water. The provision of a Class $\mathrm{C}$ rated solution is required by Part $\mathrm{L}$ of the building regulations for non domestic buildings but unfortunately there is not such a requirement for domestic buildings.

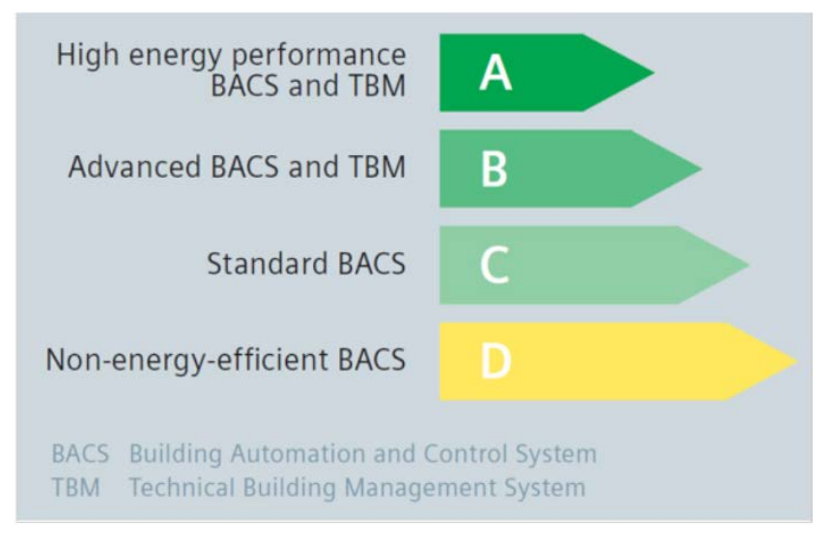

BACS and TBM use intelligent building technology to achieve environmental zone controls; typically to control the environmental conditions (i.e. temperature, ventilation rate, etc.) in individual zones (i.e. rooms or areas) within a building and the supply of services to them. They deliver not only economic savings, but comfort and flexibility while at 
the same time future proofing the installation. A well designed TBM system provides system information and analytics, identifying in advance component failures reducing the down time of a system.

\section{Methodology of collecting the evidences}

The method that was followed in the collection of the qualitative evidences comprised of a combination of research on the relevant legislation of London's construction industry. During the research stage primary and secondary data were collected. The sources of primary data were current (SAP2012) and proposed (SAP10) legislation, and for secondary data was the analysis of online discussions and forums.

The data collected through the research was benchmarked with the data collected from conversations with subject matter experts at industry events. That resulted in added value to the research and therefore moved from qualitative only, to a mixed method research.

The gathered information from speaking with subject matter experts were used to collect as many insights as possible. Understanding the Intelligent Building market was only one part of the research. The subject matter experts analysed a much broader topic including perceptions and effectiveness of buildings regulation (i.e. London Plan, Part L etc) which the secondary data did not address.

\section{Conclusion}

SAP10 is an updated calculation methodology to better evaluate the energy performance of the proposed, and subsequent as-built dwelling.

There is no doubt that the proposed key changes detailed within will be warmly welcomed across the construction industry.

The change in carbon factors means that electric heating is more favourable. However, electricity is almost four times as expensive as gas and therefore this new carbon factor could unintendedly result in higher heating bills.

As well as this, having greener electricity means generating electricity on site will not have the same affect in reducing carbon footprint, as it does today. PV systems and/or CHP units will have minimal impact on trying to improve the EPC rating and SAP scores.

Since electric heating becomes favourable, it is reasonable to suggest that electric underfloor heating will become more desirable, especially since it lends itself to off-site and modularisation construction.

The updated heating pattern results in an overall less heating demand. A challenge might be to try to further reduce this demand, by the implementation of intelligent control systems.
The more detailed calculation of hot water demand will potentially result in higher energy use in dwellings especially with electric showers.

In summary, it is acknowledged that the update, does endeavour to better reflect the actual energy systems in a dwelling, as well as the UK's advances in decarbonising our energy supplies.

However, it is felt that the results of the calculation methodology are still a long way off being a true reflection of how our dwellings actually perform.

Until post occupancy evaluations via intelligent building systems and/or extensive metering, becomes the norm for new dwellings and refurbishments, there is no way to truly evaluate exactly how good or bad our dwellings are performing.

Perhaps a more comprehensive simulation methodology similar to that used for non-domestic buildings would give a truer reflection of energy performance, however it is the operational energy, and ultimately how we use and manage our buildings, which is most significant in our quest to reducing carbon footprints.

\section{References}

\section{Conference paper}

Gavin M, John A and John C (2013) Benchmarking the effect of weather data upon energy estimation of UK homes, CIBSE Technical Symposium, Liverpool John Moores University, Liverpool, UK, pp. 2

\section{Reports}

SAP2012 - The government's standard assessment SAP10 - Specification

Technical Note 5 - Changes from SAP2012 to SAP10

\section{Websites}

\section{Website as main reference}

https://www.cibse.org/getmedia/670b20f8-a3a8-4c62-9df1ed6b1bacce84/TS2013-Additional-session-Paper-1.pdf.aspx https:/files.bregroup.com/sap/tnote-05_changes-from-sap2012-to-sap-10_v1_0.pdf

www.buildenergy.co.uk/blog/sap-10-released-whats-new/ www.elmhurstenergy.co.uk/sap-10-analysis-of-changes www.benuk.net/gla-energy-assessment-guidance.html www.cibsejournal.com/general/sap-in-building-regulations/

\section{Websites as further information}

www.c80solutions.co.uk/nine-key-changes-in-sap-10/ https://www.cibsejournal.com/opinion/unregulated-energywhy-we-should-car 